\title{
ANALISIS HUBUNGAN KEPATUHAN PENGGUNAAN ANTIASMA DENGAN KUALITAS HIDUP PASIEN ASMA DI RUMAH SAKIT KHUSUS PARU RESPIRA UPKPM YOGYAKARTA PERIODE FEBRUARI-APRIL 2013
}

\author{
Ika Alfinnisa Majida ${ }^{{ }^{*}}$, Tri Murti Andayani ${ }^{2}$, Okti Ratna Mafruhah ${ }^{3}$ \\ 1,3 Jurusan Farmasi, Fakultas Matematika dan IImu Pengetahuan Alam Universitas Islam Indonesia \\ ${ }^{2}$ Fakultas Farmasi Universitas Gadjah Mada Yogyakarta
}

*email: ikaalfinnisa204@gmail.com

\begin{abstract}
ABSTRAK
Prevalensi asma yang terus meningkat menjadi perhatian bagi tenaga kesehatan. Kepatuhan pasien asma dalam penggunaan obat dan terwujudnya kualitas hidup pasien yang baik menjadi tujuan utama dalam penatalaksanaan asma. Penelitian ini bertujuan untuk mengetahui hubungan antara kepatuhan penggunaan antiasma dengan kualitas hidup pasien asma. Populasi target dalam penelitian ini adalah semua pasien rawat jalan yang menggunakan terapi anti asma pada tahun 2012. Sampel penelitian ini adalah pasien asma dewasa dengan kategori asma menetap. Sebanyak 72 pasien diambil secara purposive dari populasi target. Penelitian ini menggunakan metode penelitian non-eksperimental dengan rancangan cross sectional. Pengambilan data dilakukan secara concurrent dan retrospektif. Tingkat kepatuhan pasien diukur menggunakan kuesioner MMAS (Morisky Medication Adherence Scale) dan kualitas hidup pasien diukur menggunakan AQLQ (Asthma Quality of Life Questionnaire). Hasil penelitian menunjukkan $52,78 \%$ pasien memiliki kepatuhan rendah dan sebesar 47,22\% pasien memiliki kepatuhan sedang. Faktor yang berhubungan secara signifikan dengan kepatuhan adalah pola kunjungan pasien. Jumlah pasien asma dengan kualitas hidup kurang baik sebesar 30,56\% dan pasien dengan kualitas hidup sedang sebesar $69,44 \%$. Penelitian menyimpulkan bahwa tidak terdapat hubungan antara kepatuhan penggunaan antiasma dengan kualitas hidup pasien asma $(p=0,842)$.
\end{abstract}

Kata kunci : kepatuhan, pasien asma, kualitas hidup, AQLQ

\begin{abstract}
The prevalence of asthma is increasing concern for health workers. Compliance of patients with asthma in the use of drugs and the quality of life of patients become a major goal in the management of asthma. This study aims to determine the relationship between the use antiasma compliance with the quality of life of patients with asthma. The target population in this study were all outpatients who use anti-asthma therapy in 2012 sample were adult asthma patients with persistent asthma category. A total of 72 patients were taken by purposive of the target population. This study used a nonexperimental study with cross-sectional design. Data were collected concurrently and retrospectively. The level of patient compliance was measured using a questionnaire MMAS (Morisky Medication Adherence Scale) and patient quality of life was measured using the AQLQ (Asthma Quality of Life Questionnaire). The results showed $52.78 \%$ of patients have low adherence and amounted to $47.22 \%$ of patients had moderate adherence. The number of asthma patients with poor quality of life by $30.56 \%$ and the quality of life of patients is at $69.44 \%$. The study concludes that there is no relationship between the use antiasma compliance with the quality of life of patients with asthma $(p=0.842)$.
\end{abstract}

Keywords: adherence, asthma patients, quality of life, AQLQ 


\section{PENDAHULUAN}

Asma merupakan penyakit kronis saluran pernapasan yang ditandai oleh inflamasi, peningkatan reaktivitas terhadap berbagai stimulus, dan sumbatan saluran napas yang bisa kembali spontan atau dengan pengobatan yang sesuai. Asma merupakan penyakit yang masih menjadi masalah kesehatan masyarakat yang serius di berbagai negara seluruh dunia dengan kekerapan yang bervariasi di setiap negara dan cenderung meningkat di negara berkembang (Anonim, 2002). Prevalensi asma adalah $1 \%-8 \%$ dari seluruh populasi di berbagai negara (Anonim ${ }^{\mathrm{a}}$, 2009). Sepuluh persen (10\%) penduduk Indonesia diperkirakan mengidap asma dalam berbagai bentuk (Gershwin, 2005).

Asma memiliki dampak buruk yaitu penurunan kualitas hidup, penurunan produktivitas, penyebab ketidakhadiran di sekolah, peningkatan biaya kesehatan, risiko perawatan di rumah sakit bahkan kematian. Asma juga dapat menyebabkan gangguan aktivitas sehari-hari dan gangguan emosi (cemas, depresi) (Anonim, 2002), sehingga tujuan utama penatalaksanaan asma adalah meningkatkan dan mempertahankan kualitas hidup agar pasien asma dapat hidup normal tanpa hambatan dalam melakukan aktivitas sehari-hari.

$$
\text { Seiring dengan perlunya }
$$

mengetahui hubungan antara terapi yang baik dan efektivitas terapetik, baik peneliti maupun tenaga kesehatan harus memahami faktor-faktor yang berhubungan dengan kepatuhan pasien (Anonim, 2007). Meskipun pengobatan efektif telah dilakukan untuk menurunkan morbiditas karena asma, efektivitas hanya tercapai jika penggunaan obat telah sesuai (Anonim, 2007).

Peneliti merasa penting melakukan penelitian tentang hubungan kepatuhan penggunaan obat dengan kualitas hidup pasien asma, mengingat pengobatan asma pada kategori merupakan long term medication, sehingga kepatuhan pasien dalam menggunakan obat sangat diharapkan (Anonim, 2007).

Pada tahun 2012 jumlah pasien penyakit asma di Rumah Sakit Khusus Paru Respira UPKPM Yogyakarta cukup banyak dan merupakan peringkat kedua setelah bronkhitis, serta di rumah sakit ini belum pernah dilakukan penelitian tentang hubungan kepatuhan penggunaan obat dengan kualitas hidup pasien asma.

Tujuan penelitian ini adalah untuk mengetahui hubungan antara kepatuhan penggunaan antiasma dengan kualitas hidup pasien asma di Rumah Sakit Khusus Paru Respira UPKPM Yogyakarta. Hasil penelitian diharapkan dapat menjadi referensi untuk melakukan evaluasi penggunaan antiasma pada pasien asma untuk mewujudkan kualitas hidup pasien yang lebih baik.

\section{METODE PENELITIAN}

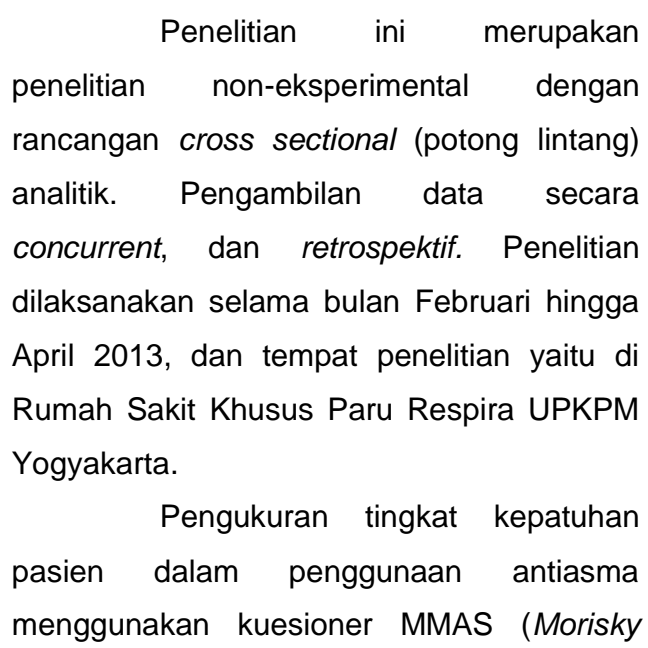


$\begin{array}{llr}\text { Medication } & \text { Adherence } & \text { Scale) dan } \\ \text { pengukuran } & \text { kualitas hidup pasien }\end{array}$ menggunakan AQLQ (Asthma Quality of Life Questionnaire).

Populasi target penelitian ini adalah semua pasien asma rawat jalan yang menggunakan terapi antiasma di Rumah Sakit Khusus Paru Respira UPKPM Yogyakarta pada tahun 2012. Populasi terjangkau penelitian ini adalah semua pasien asma rawat jalan yang menggunakan terapi antiasma di Rumah Sakit Khusus Paru Respira UPKPM Yogyakarta selama bulan Februari - April 2013.

1. Kriteria inklusi
a. Pasien asma menetap rawat jalan telah menjalani pengobatan minimal 3 bulan
b. Usia pasien antara 18 sampai 65 tahun
c. Pasien bersedia menjadi responden

2. Kriteria eksklusi

Pasien memiliki penyakit pernafasan yang lain (TBC, Bronchitis) dan penyakit kronik lainnya.

Metode pengambilan sampel menggunakan Purposive Sampling. Data primer adalah data yang diperoleh langsung dari jawaban pasien yaitu data demografi pasien (usia, jenis kelamin, tingkat pendidikan, status pernikahan, status merokok dan alamat pasien) dan data hasil wawancara dan pengisian kuesioner MMAS (Morisky Medication Adherence Scale) dan Asthma Quality Life of Questionnaire (AQLQ). Data sekunder adalah data yang diperoleh berdasarkan data rekam medik pasien yaitu data penyakit asma pasien dan terapi obat yang diterima dan digunakan pasien. Proses pengambilan data dilakukan peneliti dengan cara mewawancarai dan memberikan kuesioner AQLQ kepada pasien asma yang bersedia menjadi responden dengan menandatangani informed consent. Peneliti juga mengambil data melalui kartu rekam medik pasien untuk pengumpulan data sekunder.

Analisis data menggunakan analisis deskriptif untuk mengetahui gambaran karakteristik pasien, pengobatan pasien, skor kepatuhan dan skor kualitas hidup pasien asma. Selain itu, untuk mengetahui hubungan antara faktor usia, jenis kelamin, tingkat pendidikan, durasi asma, jumlah item obat, bentuk sediaan terapi yang diterima dan pola kunjungan berobat menggunakan analisis chi-square.

\section{HASIL DAN PEMBAHASAN}

\section{Gambaran karakteristik pasien asma}

Gambaran karakteristik pasien asma dalam penelitian ini tercantum dalam Tabel 1. 
Tabel 1. Gambaran karakteristik pasien asma rawat jalan di Rumah Sakit Khusus Paru Respira UPKPM Yogyakarta

\begin{tabular}{llcc}
\hline \multicolumn{1}{c}{ Variabel } & Kategori & Jumlah (orang) & $\begin{array}{c}\text { Persentase (\%) } \\
\text { (n = 72) }\end{array}$ \\
\hline Umur & $\leq 45$ tahun & 40 & 55,6 \\
& $>45$ tahun & 32 & 44,4 \\
Jenis Kelamin & Perempuan & 25 & 34,72 \\
& Laki-laki & 47 & 65,28 \\
Tingkat Pendidikan & SMA & 58 & 80,56 \\
& $>$ SMA & 14 & 19,44 \\
Durasi Asma & $>5$ tahun & 26 & 36,11 \\
& $\geq 5$ tahun & 46 & 63,89 \\
Jumlah Item Obat yang & $>3$ item & 45 & 62,5 \\
Diterima & $>3$ item & 45 & 62,5 \\
Bentuk sediaan Terapi & Oral & 54 & 75 \\
& Inhalasi + Oral & 18 & 25 \\
Pola Kunjungan Berobat & Rutin & 34 & 47,22 \\
& Jika Ada Keluhan & 38 & 52,78 \\
\hline
\end{tabular}

\section{Gambaran pengobatan pasien asma}

Golongan dan jenis obat antiasma
Khusus Paru Respira UPKPM Yogyakarta tercantum dalam Tabel 2.

pasien asma rawat jalan di Rumah Sakit

Tabel 2. Golongan dan jenis obat antiasma pasien asma rawat jalan di Rumah Sakit Khusus Paru Respira UPKPM Yogyakarta

\begin{tabular}{|c|c|c|c|}
\hline Golongan Obat & Macam Obat & $\begin{array}{l}\text { Jumlah } \\
\text { pasien } \\
\text { (orang) }\end{array}$ & $\begin{array}{l}\text { Persentase (\%) } \\
(\mathbf{n}=72)\end{array}$ \\
\hline Obat Pelega/ & Agonis $\beta-2$ kerja cepat & & \\
\hline Reliever Asma & Salbuta-mol sulfat (inhalasi) & 10 & 13,89 \\
\hline \multirow[t]{2}{*}{ (Bronkodi-lator) } & Salbuta- mol (oral) & 39 & 54,16 \\
\hline & $\begin{array}{l}\text { Metilsantin } \\
\text { Teofilin (oral) } \\
\text { Aminofilin (oral) }\end{array}$ & $\begin{array}{c}8 \\
48\end{array}$ & $\begin{array}{l}11,11 \\
66,67\end{array}$ \\
\hline Obat Pengontrol & Kortikoste-roid sistemik & & \\
\hline Asma & Metil Predniso-Ion & 63 & 87,5 \\
\hline \multirow[t]{3}{*}{ (Antiinfla- masi) } & $\begin{array}{l}\text { Deksame-tason } \\
\text { Agonis } \beta-2 \text { kerja lama }\end{array}$ & 11 & 15,28 \\
\hline & Prokaterol (inhalasi) & 1 & 1,39 \\
\hline & Flutica-son+Sal- meterol (inhalasi) & 10 & 11,11 \\
\hline
\end{tabular}

Prinsip penatalaksanaan asma tercantum dalam Keputusan Menteri Kesehatan Republik Indonesia (KeMenKes RI) tahun 2008 yaitu diklasifikasikan menjadi penatalaksanaan asma akut/saat serangan dan penatalaksanaan asma jangka panjang (Anonim $^{b}$, 2009). Terapi untuk mengatasi serangan akut pasien yaitu dengan diberikan obat pelega dan untuk mengontrol asma serta mencegah terjadinya serangan pasien diberikan obat pengontrol.

\section{Gambaran kepatuhan pasien asma}

Menurut Horne (2005), istilah yang tepat untuk kepatuhan dalam mengkonsumsi obat adalah adherence yaitu suatu perilaku pasien untuk mentaati saran-saran atau prosedur dari dokter tentang penggunaan obat, yang sebelumnya didahului oleh proses konsultasi antara pasien (dan atau keluarga pasien sebagai orang kunci dalam kehidupan pasien) dengan dokter sebagai penyedia jasa medis (Horne, 2005). 
Tabel 3. Gambaran tingkat kepatuhan pasien asma rawat jalan di RSKP Respira UPKPM Yogyakarta

\begin{tabular}{cccc}
\hline Variabel & Kategori & Jumlah & $\begin{array}{c}\text { Persentase (\%) } \\
(\mathbf{n}=\mathbf{7 2})\end{array}$ \\
\hline Kepatuhan & Rendah & 38 & 52,78 \\
& Sedang & 34 & 47,22 \\
& Tinggi & 0 & 0 \\
\hline & Total & $\mathbf{7 2}$ & $\mathbf{1 0 0}$ \\
\hline
\end{tabular}

Hasil penelitian yang lain menunjukkan bahwa ketidakpatuhan pasien asma dalam menjalani pengobatan dipengaruhi oleh beberapa faktor. Faktorfaktor yang lebih banyak mempengaruhi ketidakpatuhan pasien asma adalah pemahaman yang buruk tentang pengobatan, pasien kurang memahami dalam teknik menggunakan inhaler dan pasien lupa menggunakan obat (Hinchageri et al, 2012).

\section{Faktor-faktor yang berhubungan dengan} kepatuhan

1. Korelasi umur dengan kepatuhan terapi

Dalam penelitian ini hubungan antara umur dengan kepatuhan terapi pasien memiliki nilai signifikansi $p>0,05$, yaitu 0,065 , sehingga dapat dikatakan umur pasien tidak berhubungan secara signifikan dengan kapatuhan pasien.

\section{Korelasi jenis kelamin dengan kepatuhan terapi}

Data hasil penelitian menunjukkan jenis kelamin tidak berhubungan secara signifikan dengan kepatuhan terapi pasien asma dengan nilai signifikansi $p \quad 0,690$. Artinya jenis kelamin pasien asma dalam penelitian ini tidak mempengaruhi secara signifikan terhadap kepatuhan penggunaan obat. Jenis kelamin pasien lebih menggambarkan keadaan fisik dan emosi pasien. Menurut Juniper et al (2004), menyebutkan kondisi emosional pasien asma dipengaruhi oleh jenis kelamin, dan pasien perempuan memiliki risiko emosi lebih besar daripada pasien laki-laki. Sehingga jenis kelamin pasien lebih mempengaruhi kualitas hidup pasien.

3. Korelasi tingkat pendidikan dengan kepatuhan terapi

Data hasil penelitian menunjukkan tingkat pendidikan tidak berhubungan secara signifikan dengan kepatuhan terapi pasien asma dengan nilai signifikansi $p \quad 0,715$. Tingkat pendidikan seorang pasien berhubungan dengan pengetahuan pasien. Semakin tinggi tingkat pendidikan maka pola berfikir seseorang semakin baik salah satunya terhadap kepatuhan dalam mengkonsumsi obat sebagai bentuk kesadaraan untuk mengontrol asmanya. Namun, tingkat pendidikan yang tinggi belum tentu memiliki pemahaman tentang penyakit asma dan pengobatannya juga tinggi.

\section{Korelasi durasi asma dengan kepatuhan terapi}

Data penelitian menunjukkan nilai signifikansi sebesar $0,263(p>0,05)$ sehingga dapat dikatakan bahwa tidak terdapat hubungan yang signifikan antara durasi asma dengan kepatuhan terapi pasien asma. Hasil tersebut sesuai dengan penelitian

\section{Korelasi jumlah item obat yang} diterima dengan kepatuhan terapi

Hasil analisis chi-square menunjukkan bahwa jumlah item obat yang diterima pasien tidak berhubungan signifikan 
dengan kepatuhan terapi pasien asma karena nilai signifikansi $p>0,05$, yaitu 0,067

Berdasarkan hasil wawancara yang dilakukan terhadap pasien bahwa sebagian besar pasien tidak merasa keberatan dengan jumlah item obat yang diterima yaitu sebesar 45 pasien (62,5\%). Kewajiban pasien untuk menjalani terapi dengan rutin, didukung adanya kesadaran dalam hal minum obat, membuat pasien tidak mempermasalahkan seberapa banyak jumlah item obat yang harus diminum. Hal tersebut juga dapat disebabkan dukungan keluarga yang menimbulkan motivasi bagi pasien untuk meminum obat.

\section{Korelasi bentuk sediaan terapi yang diterima dengan kepatuhan terapi}

Hubungan antara bentuk sediaan terapi yang diterima dengan kepatuhan terapi memiliki nilai signifikansi $p>0,05$, yaitu 0,413 , sehingga dapat dikatakan bentuk sediaan terapi yang diterima pasien tidak berhubungan secara signifikan dengan kepatuhan terapi pasien asma.

Bentuk sediaan obat yang diterima pasien tidak menjamin kepatuhan pasien dalam menggunakan obat. Sediaan inhalasi yang diasumsikan sulit digunakan bagi pasien, hal tersebut tidak berlaku ketika pasien mengetahui cara menggunakan sediaan inhalasi. Sediaan oral yang diasumsikan mudah digunakan, hal tersebut tidak berlaku ketika pasien kesulitan dalam menelan obat. Sehingga bentuk sediaan terapi tidak memiliki hubungan secara signifikan dengan kepatuhan dalam mengkonsumsi obat.

\section{Korelasi pola kunjungan berobat} dengan kepatuhan terapi

Berdasarkan hasil analisis chi-
square menunjukkan karakteristik pola kunjungan berobat memiliki nilai signifikansi $p<0,05$, yaitu 0,019 , sehingga dapat dikatakan pola kunjungan berobat memiliki hubungan positif, yang signifikan dengan kepatuhan pasien dalam mengkonsumsi obat.

Pola kunjungan berobat merupakan pemanfaatan penggunaan fasilitas kesehatan yang disediakan. Jarak tempat tinggal pasien dengan rumah sakit diasumsikan mempengaruhi mudah tidaknya akses pasien ke rumah sakit. Hasil wawancara kepada pasien menunjukkan sebagian besar pasien tidak merasa kurang akses dalam menjangkau fasilitas rumah sakit yaitu sebesar (72,22\%). Sebagian besar pasien menilai positif terhadap pelayanan Rumah Sakit Khusus Paru Respira UPKPM Yogyakarta dibuktikan dengan hasil wawancara kepada pasien, bahwa sebesar 95,83\% menyatakan tenaga kesehatan baik dokter, apoteker maupun perawat memberikan informasi terkait pengobatan serta pasien mendapat dukungan yang positif dari tenaga kesehatan terkait penyakit asma dan pengobatannya.

Hasil penelitian ini sesuai dengan penelitian Febrianti (2010) yang menyatakan bahwa pola kunjungan berobat memiliki hubungan yang signifikan dengan kepatuhan pasien dalam penggunaan obat.

\section{Gambaran kualitas hidup pasien asma}

Gambaran kualitas hidup pasien di dalam penelitian dibagi menjadi 3 kategori, yaitu kurang baik, sedang, dan baik, yang ditunjukkan dalam Tabel 4. 
Tabel 4. Gambaran skor kualitas hidup pasien asma rawat jalan di RSKP Respira UPKPM Yogyakarta

\begin{tabular}{cccc}
\hline Variabel & Kategori & Jumlah & $\begin{array}{c}\text { Persentase (\%) } \\
(\mathbf{n}=\mathbf{7 2})\end{array}$ \\
\hline Kualitas & Kurang baik & 22 & 30,56 \\
hidup & Sedang & 50 & 69,44 \\
& Baik & 0 & 0 \\
\hline & Total & 72 & 100 \\
\hline
\end{tabular}

$\begin{array}{ll}\text { Hubungan kepatuhan penggunaan } & \text { menggunakan analisis statistic chi-square. } \\ \text { antiasma dengan kualitas hidup } & \text { Hasil analisis ditampilkan sebagai berikut. }\end{array}$

Penggunaan antiasma dengan
kualitas hidup pasien diolah dengan

Tabel 5. Hasil analisis chi-square tentang hubungan antara tingkat kepatuhan dengan kualitas hidup

\begin{tabular}{ccccc}
\hline Kualitas Hidup & \multicolumn{2}{l}{ Tingkat Kepatuhan } \\
& $\begin{array}{l}\text { Rendah } \\
(n=38)\end{array}$ & $\begin{array}{l}\text { Sedang } \\
(n=34)\end{array}$ & $\mathbf{p}$ & Keterangan \\
\hline Kurang $(n=22)$ & 12 & 10 & 0,842 & Tidak terdapat hubungan \\
Sedang $(n=50)$ & 26 & 24 & & \\
\hline
\end{tabular}

\section{Ketidaksesuaian hasil dengan \\ hipotesis penelitian tersebut dapat} disebabkan karena kualitas hidup pasien asma merupakan hal yang kompleks yang dapat dipengaruhi oleh beberapa faktor. Sehingga kepatuhan penggunaan obat dalam penelitian ini tidak signifikan mempengaruhi kualitas hidup pasien, tetapi lebih dipengaruhi oleh faktor lain. Dalam konsep penelitian ini peneliti mencantumkan faktor-faktor yang diasumsikan dapat mempengaruhi kualitas hidup pasien asma. Faktor-faktor tersebut tidak dianalisis, namun hanya berdasarkan kajian literatur saja. Faktor tersebut adalah kondisi keluarga dan lingkungan.

Berdasarkan hasil wawancara jumlah pasien dengan paparan debu sering dan jarang sama besarnya yaitu $50 \%$. Paparan debu tersebut dapat di lingkungan rumah ataupun tempat kerja. Dalam pembahasan sebelumnya dijelaskan bahwa pasien dalam penelitian ini sebagian besar mendapat dukungan positif dari keluarga, sehingga meskipun dalam penelitian ini tingkat kepatuhan pasien dalam mengkonsumsi obat lebih banyak kategori rendah, namun pasien mendapat dukungan dari keluarga serta lingkungan sekitarnya yang tidak mengganggu, maka kualitas hidup pasien dalam penelitian ini lebih sedikit kategori kurang daripada kategori kualitas sedang.

Faktor kepribadian juga dapat mempengaruhi kualitas hidup. Berdasarkan penelitian yang dilakukan oleh Axelsson et al. (2009) menunjukkan bahwa kepribadian dapat mempengaruhi bagaimana pasien asma patuh terhadap pengobatan asma dan melaporkan bagaimana kondisi asmanya serta kualitas hidupnya (Axxelson, 2012). Kepribadian dalam hal ini berhubungan dengan fungsi emosi pasien. Data pada tabel IV menunjukkan bahwa rata-rata skor kualitas hidup pasien pada domain emosi adalah 4,67 (kategori sedang). 
Penelitian analisis hubungan kepatuhan penggunaan obat dengan kualitas hidup pasien asma yang dilakukan di RSKP Respira UPKPM Yogyakarta memiliki beberapa keterbatasan, diantaranya adalah periode penelitian yang terbatas serta jumlah responden yang sedikit, sehingga kurang maksimal dalam menggambarkan populasi pasien. Adapun kelemahan dari penelitian ini adalah :

1. Pemeriksaan fungsi paru tidak dilakukan, sehingga tidak dapat diketahui nilai VEP 1 (Volume Ekspirasi Paksa Pertama) atau PEF (Peak Expiratory Flow). Pemeriksaan fungsi paru sangat penting, karena merupakan salah satu pemeriksaan untuk mengetahui dan menentukan derajat penyakit asma.

2. Diagnosis asma yang ditentukan oleh dokter hanya secara umum. Penentuan pasien persisten agar dapat masuk kriteria inklusi dilakukan dengan menanyakan langsung kepada pasien mengenai frekuensi gejala yang muncul, sehingga hasilnya bersifat subyektif.

\section{KESIMPULAN}

\author{
Berdasarkan hasil analisis uji \\ statistik chi-square dengan taraf \\ kepercayaan 95\% dan taraf signifikansi \\ $p<0,05$ diperoleh hasil yaitu tidak terdapat \\ hubungan antara kepatuhan penggunaan \\ antiasma dengan kualitas hidup pasien \\ asma.
}

Saran bagi peneliti selanjutnya adalah :

a. Perlu dilakukan evaluasi kepatuhan dan kualitas hidup pasien asma dengan sampel yang lebih besar baik di Rumah Sakit Khusus Paru Respira UPKPM Yogyakarta atau di rumah sakit lain. b. Perlu dilakukan evaluasi kepatuhan dan kualitas hidup pasien asma dengan menggunakan instrumen yang lain atau mengkombinasikan instrumen. Misalnya untuk mengukur kepatuhan dapat menggunakan kuesioner dan patients estimates adherence.

c. Perlu dilakukan evaluasi faktor-faktor yang dapat mempengaruhi kualitas hidup pasien asma.

Saran bagi rumah sakit adalah :

a. Pada pasien asma diperlukan diagnosis yang lebih spesifik mengenai derajat asma yang dialaminya. Sehingga dapat memudahkan dalam mengontrol perkembangan asmanya.

b. Diperlukan adanya pengukuran pengetahuan pasien asma mengenai penyakit asma dan pengobatannya serta edukasi dalam bentuk lisan ataupun tertulis secara berkala untuk pasien mengenai penyakit asma dan pengobatannya.

c. Diperlukan konseling yang lebih efektif antara apoteker dan pasien guna meningkatkan pemahaman pasien dalam hal penggunaan obat antiasma.

\section{UCAPAN TERIMA KASIH}

Peneliti menyampaikan rasa terimakasih kepada tenaga kesehatan di Rumah Sakit Khusus Paru Respira UPKPM Yogkayakarta, Jurusan Farmasi, Fakultas Matematika dan IImu Pengetahuan Alam Universitas Islam Indonesia, serta dosen pembimbing Trimurti Andayani, Sp.FRS, Ph.D., Apt dan Okti Ratna Mafruhah, M.Sc., Apt. 


\section{DAFTAR PUSTAKA}

Anonim, 2002, Guidelines for diagnosis and management of asthma, 2nd edition, National Heart, Lung and Blood Institute, New York, 1-5

Anonim, 2007, Pharmaceutical care untuk penyakit asma, Direktorat Bina Farmasi Komunitas dan Klinik, Ditjen Bina Kefarmasian dan Alat Kesehatan, Departemen Kesehatan RI, Jakarta

Anonim $^{\mathrm{a}}$, 2009, Global Initiative for Asthma, Global strategy for asthma management and prevention, NHLBI/WHO workshop report, US National Institutes of Health, USA

Anonim $^{\mathrm{b}}$, 2009, Pedoman Pengendalian Penyakit Asma, Departemen Kesehatan R.I Direktorat Jendral Pengendalian Penyakit dan Penyehatan Lingkungan Direktorat Pengendalian Penyakit Tidak Menular, Jakarta, 5-7

Axelsson, M., Emilsson, M., Brink, E., Lundqren J., Toren, K., Lotvall, J., 2009, Personality, Adherence Asthma Control and Health-related Quality of Life in Young Adult Asthmatics, Repir Med, 103(7):103340, Department of Internal Medicine, Sahlgrenska Academy, University of Gothenburg

Febrianti, Y., 2010, Analisis Hubungan Kepatuhan Penggunaan obat dengan Kualitas Hidup Pasien Hipertensi di Puskesmas Ngemplak I Yogyakarta Periode Maret-Juni 2010, skripsi, Jurusan Farmasi, Fakultas Matematika dan IImu Pengetahuan Alam, Yogyakarta

Gershwin, L., 2005, Asthma, Gender, and ETS : Pathogenic Synergy, available from

:http://www.trdrp.org/research/PageG rant.asp/grant id=4046 (diakses 25 Desember 2012)

Hinchageri, S.S., Patil, N., Karan, K., Shalini, B., Swarnakamala, K., 2012, Assessment of Medications Adherence and Factors Affecting to Medication Adherence in Asthma Patients by Clinical Pharmacist, IRJP, 3 (3) : 211-215

Horne, R., Kellar, I., 2005, Interventions to Facilitate Adherence. Report for The national Co-ordinating Centre for NHS Service Delivery \& Organisation $R \& D$ (NCCSDO). Centre for Health Care Research, University of Brighton, Falmer, Brighton

Juniper, E., 2012, Asthma Quality of Life Questionnaires: Background, Administration and Analysis, Bosham, West Sussex

Juniper, E.F., Wisniewski, M.E., Cox, F.M., Emmett, A.H., Nielsen, K.E., O'Byrne, P.M., 2004, Relationship between quality of life and clinical status in asthma: a factor analysis, Eur Respir $J, 23(287): 91$ 